See discussions, stats, and author profiles for this publication at: https://www.researchgate.net/publication/322059303

\title{
Development and evaluation of android based notification system to determine patient's medicine for pharmaceutical clinic
}

Conference Paper · September 2017

DOI: 10.1109/EECSI.2017.8239155

\section{CITATION}

1

3 authors:

(2)

Imam Riadi

Ahmad Dahlan University

131 PUBLICATIONS 611 CITATIONS

SEE PROFILE

B. Herman Yuliansyah

Universitas Ahmad Dahlan, Indonesia

17 PUBLICATIONS 17 CITATIONS

SEE PROFILE

Some of the authors of this publication are also working on these related projects:

Project Publication View project

Project Determining the nutrition of patient based on food packaging product using fuzzy C means algorithm View project
READS

95

Ahmad Dahlan University

15 PUBlicATIONS 19 CITATIONS

SEE PROFILE 


\section{Development and Evaluation of Android Based Notification System to Determine Patient's Medicine for Pharmaceutical Clinic}

\author{
Imam Riadi \\ Department of Information System \\ Universitas Ahmad Dahlan \\ Yogyakarta \\ imam.riadi@is.uad.ac.id
}

\author{
Sri Winiarti \\ Department of Informatics \\ Universitas Ahmad Dahlan \\ Yogyakarta \\ sri.winiarti@tif.uad.ac.id
}

\author{
Herman Yuliansyah \\ Department of Informatics \\ Universitas Ahmad Dahlan \\ Yogyakarta \\ herman.yuliansyah@tif.uad.ac.id
}

\begin{abstract}
The development of science in the field of health clinical pharmacy grows rapidly in recent years. Based on the data from information was obtained that needs to be done a reparation a learning process in clinical pharmacy to produce them who as requested by users pharmaceutical graduates. According to the results of the information there is a problem that in conducting the process of determining the pharmacys drug it can be made a mistake, especially in patients who have complications disease. The process of checking conducted repeatedly to make sure a medicine that is concocted in accordance with a list of the acts of treat a patient, while patient data not yet integrated into a system that could help them in analysis and determine a drug that in accordance. Notification system that developed using android platform this, the hope can become the tools in the form of a system that can give notification to the farmasis easily accessible at any time through gadgets. Based on the results of testing with the methods alpha test can be concluded the number of feasibility this system reached $88.75 \%$. Thus notification system in the determination of medicine patients rule based as a medium learn students pharmaceutical clinic worthy to used.
\end{abstract}

Keywords—development, system; android; medicine; clinic.

\section{INTRODUCTION}

Clinical Pharmacy is the practice of pharmaceutical science in which orientation towards patient is greater than orientation towards products. The term 'pharmaceutical clinic' begins to appear in 1960 in the United States, which is a pharmaceutical discipline that emphasizes function of pharmacies as a caregiver to the patient. Pharmaceutical science aims to improve treatment outcome. The lack understanding of pharmaceutical clinic concept owned by paramedics is one of the factors causing slowness of development of pharmaceutical services in Indonesia. Is still considered or constituting peculiarity if a druggist which was originally serves prepare the drug pharmaceutical in the hospital, then to enter to ward care and monitoring the development of the treatment, especially when have recommendations treatment, as the usual be in the forward.

Based on developments, this research is conducted by

This research is supported by Ministry of Research, Technology and Higher Education in the research scheme Competitive Grant Research (Penelitian Hibah Bersaing/PHB) grant number No: 011/HB-LIT/III/2016 on 15 March 2016. running the application on top of Android mobile operating system, which has relatively much users and has several easiness to join with other systems.

\section{CURRENT RESEARCH}

Literature study that has been done to look references associated to this research topic refers to the article and scientific publication. One of paper stated that warning systembased technology the future holds the promise to give increased access to information security and support cognitive to each of the components of the process warning. Specifically, the aim of enhancing safety users through decisions in connection with the risks the quality of being more high could be achieved by honing the skills interactive technology and their ability to personalisasi information admonition modification content a dynamic [1]. Different by articles formerly research used the systematic to analyze, design, implement, and evaluate system notes nursing electronic based terminology. Research is able to to evaluate the efficacy of a user interface and vocabulary developed, so as to give basic for improvement in order to further research [2]. Next associated research stated that information is main requirements for most people. By using a smartphone, information can be obtained anywhere the location is in a short time. The use of technology in mobile manner the most widely used today is the day smartphone with an operating system Android. Besides used to seek for information, smartphone can also be used to display map and navigation [3].

\section{BASIC THEORY}

\section{A. Health Information Systems}

The advancements in semiconductor and networking technologies resulted in a public health home-care service called Telecare Medicine Information Systems (TMIS). TMIS medical server connects to the patient Body Area Network (BAN) via public Internet and retrieves the real time patient's health data related to heartbeat, blood pressure, etc. [4].

Outpatient clinics are demanding environments. The function of clinics may be different from county to county. 
While in the US, most outpatient clinics share some common steps, such as patient checking in, patient data input and updating, resident seeing the patients, and checking out, etc. It's crucial to provide patients with safe, high-quality care. It's important that clinics run effectively and efficiently [5].

Health information system is an information management in the entire extent government in systematically in the execution of public services. The act of regulation that information system health is minister for health decree number $004 /$ menkes $/ \mathrm{SK} / \mathrm{I} / 2003$ on policies and strategies decentralization the field of health and minister for health decree number 932/menkes/SK/VIII/2002 on implementation guidelines of development the report system district health information. Only of the content of the two ministers for health decree containing weakness where they only see system health information from a management health, not utilizing state of the art information technology and no connection to the national information system. Information and communication technology have not elaborated details to make the data served are inappropriate and not punctual.

\section{B. Android}

Android powers hundreds of millions of mobile devices in more than 190 countries around the world. It's the largest installed base of any mobile platform and growing fast - every day another million users power up their Android devices for the first time and start looking for apps, games, and other digital content. Android gives you a world-class platform for creating apps and games for Android users everywhere, as well as an open marketplace for distributing to them instantly [6].

Along with the popularity of mobile devices and their growth are created a range of platforms and applications programming environments for them. Different platforms of operating systems like Symbian OS, PalmOS, J2ME, Blackberry, Windows Mobile, iOS and Android are currently used by equipment vendors in their mobile devices [7].

Android have some platform version that supported many devices as a target installation an application. Android having some of the features of them [8]:

1. Access to Hardware, Including Camera, GPS, and Sensors

2. Data Transfer using Wi-Fi, Bluetooth and NFC

3. Maps, Geocoding and Location-based Services

4. Background Services

5. SQLite Database for Data Storage and Retival

6. Shared Data and Inter-Application Communication

7. Extensive Media Support and 2D/3D Graphics

8. Cloud to Devices Messaging

9. Optimized Memory and Process Management.

Android devices have become a special and "anywhere, everywhere" computational resource for a wide range of requirements. It supports various types of application starting from Electronic commerce to navigation, from location-based services to video games entertainments and so on. Due to its 'mobile' nature, it allows people to carry high computational power in their hands where the computational power is comparable against that of a desktop or laptop [9].

\section{Rules}

Expert system is a kind of computer program that can simulate the thought of human expert. It can solve the complex problems that can be only answered by a particular field expert. And fault diagnosis expert system is also a computer program that utilizes the experiences, technologies and reasoning methods of support experts to detect, isolate and identify the fault of some object. It has a wealth of experiences and expertise, the capability of symbolic manipulation and uncertain information processing, the self-knowledge, clearly separated knowledge base and inference engine [10].

Expert Systems is a branch of Artificial Intelligence that makes extensive usage of specialized knowledge to solve problems at the human expert level [11].

The development of application using the concept of health information system required components: the knowledge base, the rules base and management dialogue as a medium communication between computer and human. In this research focuses to display notification system in the process of giving decision used rule based. The rules bases are built on the base of knowledge, which has obtained before. Table 1 is a form of representation knowledge by use the model production of rules.

TABLE I. THE REPRESENTATION OF KNOWLEDGE WITH THE PRODUCTION OF RULES

\begin{tabular}{|c|c|}
\hline $\begin{array}{l}\text { Rule } \\
\text { Code }\end{array}$ & Rules \\
\hline [R1] & 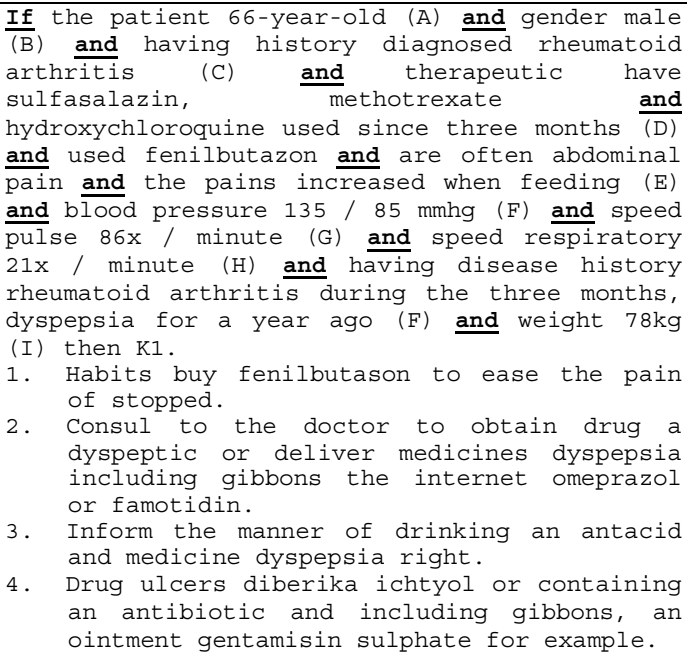 \\
\hline [R2] & $\begin{array}{l}\text { If the patient } 28(\mathrm{~J}) \text { years and gender women } \\
(\mathrm{K}) \text { and having history pregnant } 30 \text { sunday (L) } \\
\text { and toothache (M) and blood pressure } 130 / 80 \\
\text { mmh (O) and the pulse } 82 \mathrm{x} / \text { minute (P) and } \\
\text { speed respiratory } 23 \times / \text { minute (Q) and the } \\
\text { acts of the use of a drug sulfasalazin, } \\
\text { methotrexate, ydroxychloroquine, mylanta since } \\
3 \text { months ago from and weight } 87 \mathrm{~kg}(\mathrm{~S}) \text { and } \\
\text { family history father hypertension and mother } \\
\text { dm type } 2 \text { them, then } \\
\text { Habits consumption herbs omitted in the } \\
\text { pregnancy (K2) } \\
1 . \text { A drug that the best kind is paracetamol } \\
\text { or to the doctor to obtain a prescription } \\
\text { analgetik for pregnant women. }\end{array}$ \\
\hline
\end{tabular}

From Table 1 was found that the process tracking used to make a decision the act of on a system notification the determination of a cure for clinical pharmaceutical this uses the 
tracking forward or forward chaining. In making graph tracking to ease made served with use symbolic letters. Symbol letters represent representation knowledge of any facts so to conclusion. Such as the Figure 1 is illustration of the representation of knowledge to the first case (1). Letter A, B and so on as symbolic that is a representation of any the facts are presented in table 2 . With the form of the rules symbolized by letters, so rule 1 as:

IF $A$ and $B$ and $C$ and $D$ and $E$ and $F$ and $G$ and $H$ Then K1

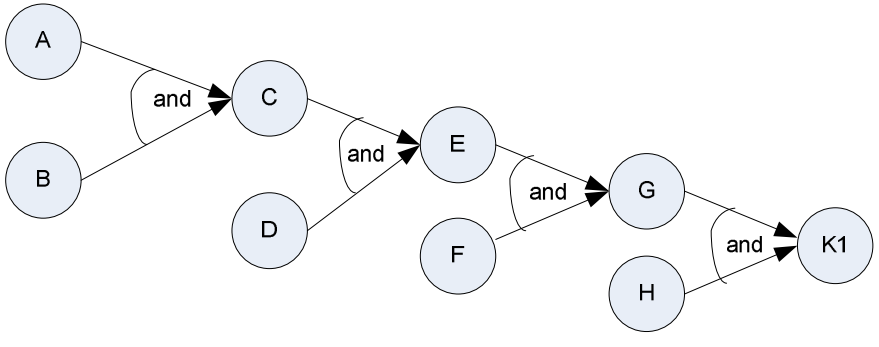

Fig. 1. Ways of working method forward chaining

Figure 1 describes illustration off the grid with the methods forward chaining to rule 1 .

\section{RESEARCH METHODS}

This research is conducted through waterfall scheme that can be seen in figure 2 .

Steps as seen in figure 2, are the milestones of this research, which can be described as follows:

\section{- Requirements}

In this phase information collection related to system requirements in the development of the mobile application was done.

\section{- Design}

Based on requirements that have been found in previous stage, then system design is then conducted. It can be seen as the Figure 3.

- Implementation

After conducted the design process, then the process of application implementation will be conducted in Android OS technically.This research developed using Android Studio 2016, with the details as follows: webserver, programming language, and should be run at an operating system android 3.X - 6.x.

- Verification

In this phase verification and testing of the system is conducted. Alpha testing is carried out for this purpose.

- Maintenance

In this phase evaluation will be done based on user input on the end user tests that user has done on the application.

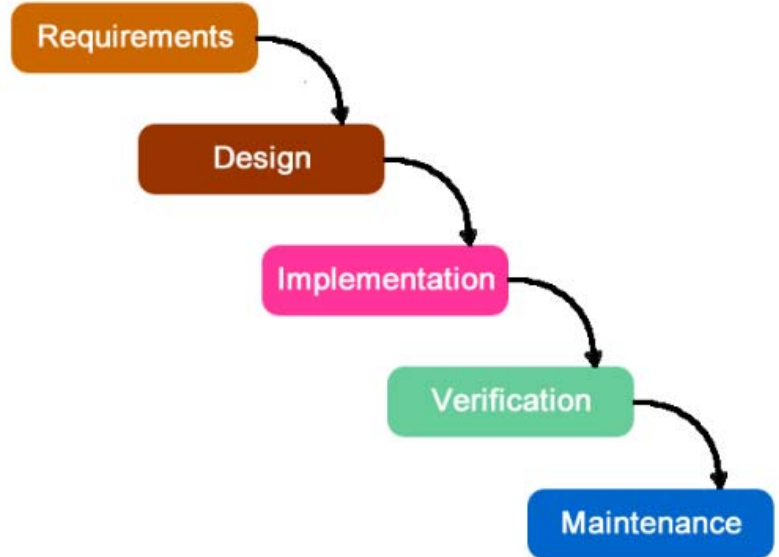

Fig. 2. The development of methods waterfall mobile application

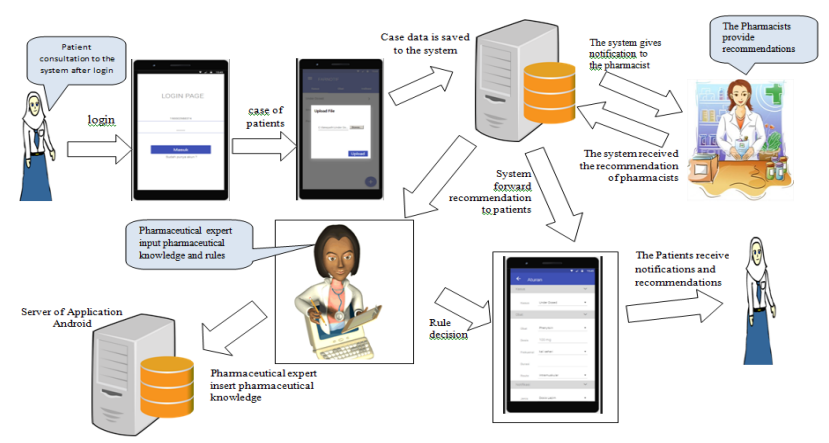

Fig. 3. Design notification android system based

\section{RESULT}

\section{A. Implementation}

Application has been implemented and has features such as login, see and the addition of cases and medicine. Figure 4 show function login, where users can $\log$ in by using facilities from login data system. Figure 5 and Figure 6 shows data cases and drugs have been put into the program. Program code is the source for login function. On the program codes, android will have three pieces of widget namely 2 edit text and 1 button. The edit text contains username and password then button will call method login for examining the condition of username and the passwords that were filled.

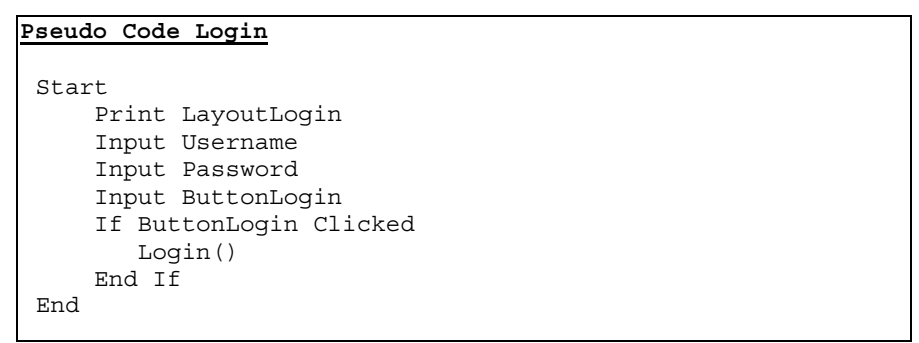




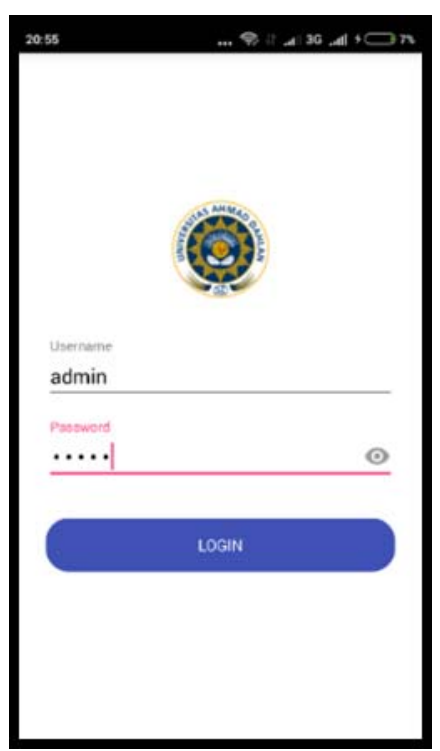

Fig. 4. Login Form

If the user wants to perform the addition of cases and remedies, from Figure 5 and Figure 6 can affect action click on the Add button, and then fill in the data of the case and the drug data in Figure 7 and Figure 8. Program code indicates the activities to increase case and drug information. The process for displaying the data field of the drug and the case is done by making a fragment, which will display a page with the name of the pager. The layout is displayed with layout format. Tabs containing the Drug and tab of cases save configuration Tab Layout.

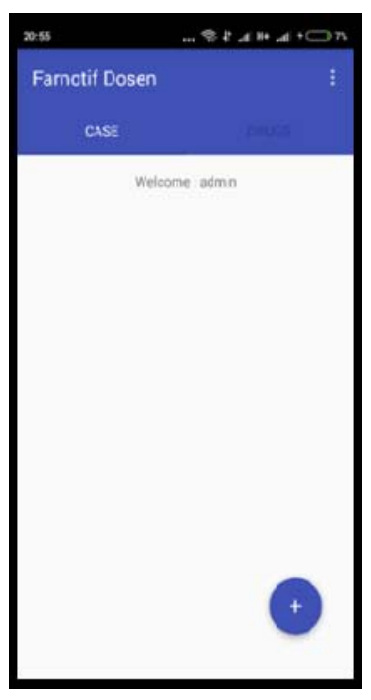

Fig. 5. Information case

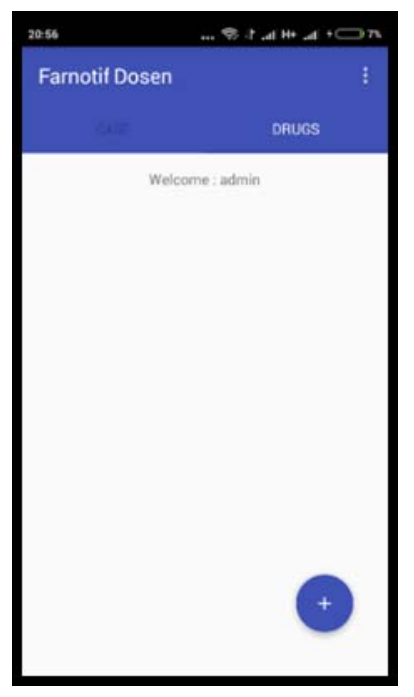

Fig. 6. A drug information data
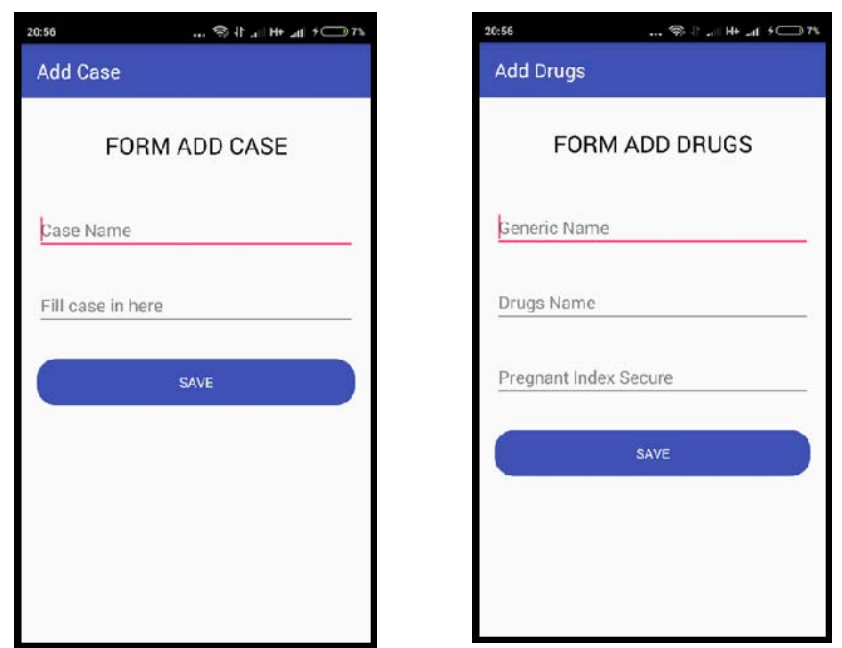

Fig. 7. Display added cases

Fig. 8. Added the appearance of a drug

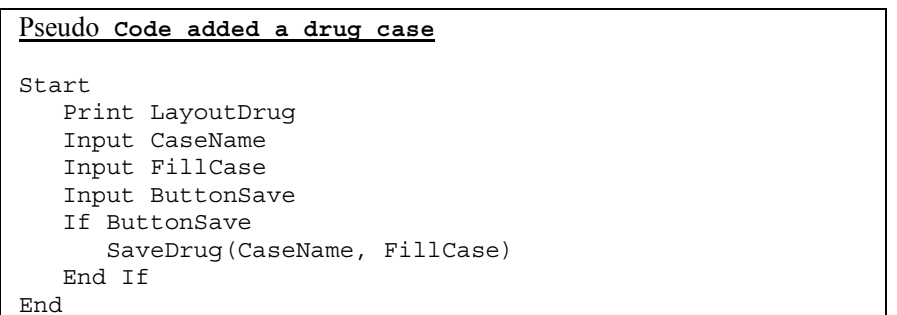

\section{B. Testing}

Tests carried out in the research uses alpha testing method, testing was done by experts from pharmaceutical, details of the calculation can be seen as on a Table 2 .

TABLE II. AlPHA TEST RESUlTS OF DATA COLLECTION

\begin{tabular}{|l|l|ccccc|}
\hline No & \multicolumn{1}{c|}{ Quistions } & SA & A & E & NA & SNA \\
\hline $\mathbf{1}$ & $\begin{array}{l}\text { Patient registration process } \\
\text { is very easy }\end{array}$ & 3 & 5 & 0 & 0 & 0 \\
Each patient needs to log & 5 & 3 & 0 & 0 & 0 \\
$\mathbf{3}$ & $\begin{array}{l}\text { into the system } \\
\text { The menu in the system easy } \\
\text { to understand } \\
\text { The process of case selection } \\
\text { is easy to use }\end{array}$ & 2 & 5 & 1 & 0 & 0 \\
$\mathbf{5}$ & $\begin{array}{l}\text { Election process of drug is } \\
\text { easy to use patient } \\
\text { The system has been running } \\
\text { well (no error) }\end{array}$ & 1 & 5 & 0 & 0 & 0 \\
$\begin{array}{l}\text { A notification message is } \\
\text { easy to understand } \\
\text { The system makes it easy to } \\
\text { understand each case } \\
\text { The system is already } \\
\text { according to user needs } \\
\text { Overall system useful for the } \\
\text { user }\end{array}$ & 2 & 4 & 4 & 2 & 0 & 0 \\
\hline & 2 & 4 & 2 & 0 & 0 \\
\hline Quantity & 29 & 42 & 9 & 0 & 0 \\
\hline
\end{tabular}

Each question in Table 2 is tested to determine the user's response while using the system. Tests are emphasized on the operation of the system such as ease of login, ease of consultation process, system response during dialogue between 
users and the system. This is important to know the percentage of user acceptance of this system.

Based on the results of testing alpha test on Table 2 obtained the result that respondents who said that really agree $36,25 \%$ as much as, of respondents who said they agreed $52.5 \%$. Thus it can be said that whole system can be expressed in accordance to be implemented. From the results of the testing can be represented in graphical form as shown in Figure 9.

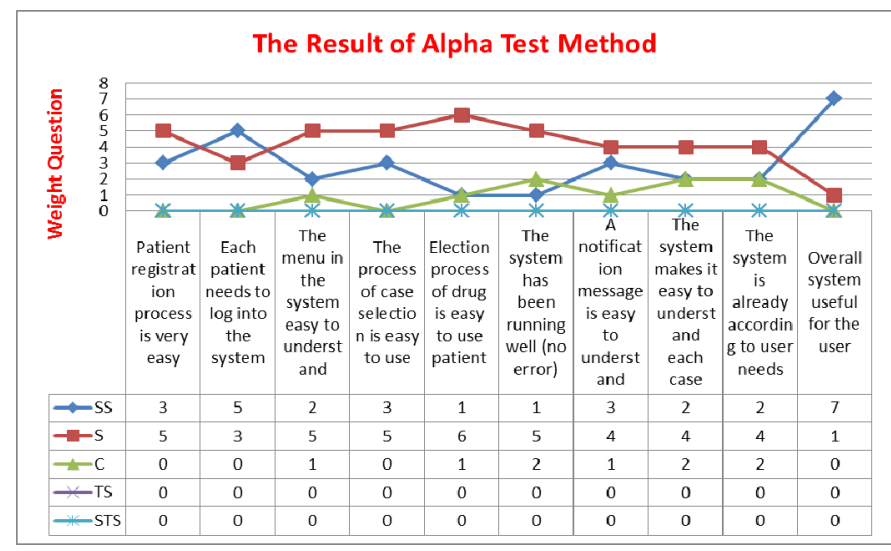

Fig. 9. A chart representation the results of testing alpha testing

\section{CONCLUSION}

This research develop a system that could give notification to the pharmaceutical clinical in giving the determination of medicine for patients when consult in pharmacies. A system that has been made this based android that supported many devices as a target installation an application. Based on the results of testing committed using alpha testing, obtained the results of $88.75 \%$ stated in accordance with a hoped-for goal. Thus notification system in the determination of medicine patients rule based as a medium learn students pharmaceutical clinic worthy to use.

\section{ACKNOWLEDGMENT}

The authors would like to thank the anonymous reviewers for their comments and suggestions that helped to improve the quality and presentation of this paper and Mukti Wibowo, Welny Putri Maharani for her help to contribution as student's researcher in this paper.

\section{REFERENCES}

[1] M.S, Wogalter, C.B. Mayhorn, "Providing cognitive support with technology-based warning systems", jurnal Ergonomics, Vol. 48, No. 5, 15, pp.522 - 533, April 2005.

[2] I.S, Cho, A.E, Hyeoun, "Development and evaluation of a terminology based electronic nursing record system", journal Study Health Technology Information. pp.498-502, 2009.

[3] G. Karya, B.E, Purnama. "Implementation of Location Base Service on Tourism Places in West Nusa Tenggara by using Smartphone" (IJACSA) International Journal of Advanced Computer Science and Applications Vol.6, No.8, pp.160-166, 2015.

[4] P.P, Jaya, M.C.M, Reddy, S. Bapana, C.S, Vorugunti, "A secure RFID protocol for Telecare Medicine Information Systems using ECC" In Wireless Communications, Signal Processing and Networking (WiSPNET), International Conference on, pp. 2295-2300. IEEE, 2016.

[5] F.Liuliu, L. Ling, "The Value of an Integrated Information System: A Case of an Out-Patient Clinic" In Enterprise Systems Conference (ES), pp.57-60. IEEE, 2014.

[6] API.Guide, "Introduction to Android “, 2016. https://developer.android.com/about/android.html

[7] S. Isak, B. Sejdiu, F. Jasharaj, "Consuming Web Services on Android Mobile Platform for Finding Parking Lots" University of Prishtina, Republic of Kosovo, (IJACSA) International Journal of Advanced Computer Science and Applications, Vol.6, No.2, pp.175-180, 2015.

[8] M. Reto. "Professional Android 4 application development" John Wiley \& Sons, 2012

[9] K.T, Udhaya, R. Senthilkumar, "CWC*-Secured distributed computing using Android devices" In Recent Trends in Information Technology (ICRTIT), International Conference on, pp.1-7. IEEE, 2016.

[10] Wen, Tianzhu, A. Xu, D. Yin, "Study on extension expert system based on production rule and its application" In Intelligent Control and Automation (WCICA), 11th World Congress on, pp. 5123-5126. IEEE, 2014.

[11] Divayana, D.G Hendra, "Development of Duck Diseases Expert System with Applying Alliance Method at Bali Provincial Livestock Office" (IJACSA) International Journal of Advanced Computer Science and Application, Vol.5, No.8, pp.48-54, 2014 